\title{
iTunes
}

\section{Breaking Barriers and Building Walls}

\author{
David Arditi \\ 601 S. Nedderman Drive \\ UH 511 \\ University of Texas at Arlington \\ Arlington, TX 76019 \\ (757) 875-1325 \\ darditi@uta.edu \\ 4/18/2013
}

Word Count: 8,331 


\title{
iTunes: Breaking Barriers and Building Walls
}

\author{
Abstract \\ With the development of online music distribution, a number of authors argued that independent \\ musicians could compete on equal ground with major record labels. In this article, I explore the effects \\ that online distribution has had on distributing music to consumers. This essay argues that through the \\ development of iTunes, the major record labels have maintained the same advantages that they held \\ through physical media distribution networks.
}

In 2001, the recording industry claimed to be in turmoil because of the widespread use of peer-2peer (p2p) file sharing software. While major record labels, represented by the Recording Industry Association of America (RIAA), panicked that they would no longer have unrestricted access to profits from music consumers, independent artists and Internet celebrants hailed $\mathrm{p} 2 \mathrm{p}$ networks as a means to circumvent the extensive national music distribution system. Historically, major record labels have been able to control the market of physical media because of expensive distribution systems (Chapple and Garofalo; Frith), but independent musicians began to circumvent these systems by using $\mathrm{p} 2 \mathrm{p}$ networks. Independent musicians and consumers predicted a new market where music could be shared online for free (Burkart and McCourt; Lessig; Park); they argued that this technology would create a place where independent musicians could distribute music without the costly distribution systems required to get CDs to stores. On the other hand, major record labels were concerned that piracy on these $\mathrm{p} 2 \mathrm{p}$ file- 
sharing networks could cause their businesses to go bankrupt. For instance, former RIAA President Cary Sherman claimed that the RIAA "believe the use of these illegal peer-to-peer services is hurting the music industry's efforts to distribute music online in the way consumers demand" (Quoted in Garrity and Christman).

Industry executives are not the only people who perpetuate the theory that digital music will be the downfall of record labels. In 2005, Kembrew McLeod posited, "these technological changes do threaten to help break the music monopoly that has existed for a century, something that, at the very least, will increase the diversity of music available to music fans" (McLeod 530531). At the time McLeod was writing, major record labels appeared to be suffering losses as their Fordist production models, which were geared toward generating large profits from a small number of superstar recording artists, seemed to be declining because consumers had more music options. While I share McLeod's hope that these "technologies threaten to erode [the major record labels'] market hegemony" (522), in hindsight, his projection could not be further from the truth because the major record labels have coopted Internet distribution. In another piece, I demonstrate that the major record labels are stronger than ever; however, here I am interested in analyzing the specific mechanisms that have enabled the majors' new business model to flourish in stark opposition to the narrative of crisis produced by the RIAA in 2001.

This paper aims to explore the inconsistency between the Internet's potential to give musicians and consumer more access to each other and the actual situation that exists for music consumption via the Internet. How have the major record labels survived in an atmosphere where mediated barriers have been eliminated? I approach this question from a cultural studies position that uses imminent critique to demonstrate the inherent contradictions that exist in the major record labels' discourse. First, this paper examines the potential for digital distribution to 
circumvent the major record labels' control over retail distribution. Second, it turns to $\mathrm{p} 2 \mathrm{p}$ software's potential and vulnerabilities. Third, it explores the impact of iTunes on the recording industry. Finally, it analyzes the further monopolization that has happened as a result of digital distribution.

\section{The Internet and Disintermediation}

The primary limitations that musicians face in producing and circulating their music is their lack of access to recording studios and lack of access to retailers. Two recent technological changes contribute to the ability of musicians to overcome these limitations. First, the development of digital recording technology makes recording technology inexpensive and small enough that most musicians can build a "home" studio to record their work. Second, the Internet provides the capacity for musicians to distribute their music without relying on selling it through "brick-and-mortar" stores across the country. While this second obstacle, distribution, is seemingly lessened by the Internet, it actually remains the greatest barriers for musicians to get their music heard.

Major record labels have an advantage distributing music because they have capital and control the means of distribution. "For a century," McLeod describes, "the major label system dominated the music industry because it owned the means of production and distribution" (527). Musicians do not produce an album that shows up magically in record stores; rather, musicians produce an album and rely on intermediaries to get the album printed and shipped to retailers. There is a whole system of intermediaries in the record labels alone (Negus), but the focus here is on the intermediaries who distribute the commodity to stores. If we assume that every album can be recorded at a high quality for little to no cost, then we should be able to assume that every album can compete in the "market place of ideas"; however, not every album is given equal 
opportunity to be consumed because albums have to be distributed to stores. There is a high cost to print and package albums, house them in storage facilities, ship them to stores, and sell them at retail outlets; ${ }^{1}$ this is to say nothing of the promotional costs that go into convincing store owners/managers to carry a particular album. Independent musicians/labels cannot compete with the major record labels until they either invest in distribution networks or find ways around the costly aspects of distributing records to stores.

When a CD sits on a store shelf, it has already incurred a number of costs that are incorporated into the price of the $\mathrm{CD}$. The price to manufacture and package each $\mathrm{CD}$ ranges from one to two dollars, depending on the number of CDs being printed and the type of packaging that comes with it (Hull, Hutchison, and Strasser). On top of the cost to manufacture the $\mathrm{CD}$ is the actual cost to get the $\mathrm{CD}$ from the manufacturer to the retailer. Most distributors charge about $\$ 1.70$ for each CD shipped (Hull, Hutchison, and Strasser 255). Additionally, the retail stores have their own costs and profits that they work into the price of a CD. A standard $\mathrm{CD}$ is sold for $\$ 12$ wholesale, but the retail price is often around $\$ 17$; this means that approximately five dollars of the price of a $\mathrm{CD}$ is a surcharge for the ability to purchase a CD at a store (Hull, Hutchison, and Strasser). The largest part of the cost of a CD is in the gross margin of the record labels, which can be from $\$ 5.51$ to $\$ 6.86$ depending on the rate of artist royalties (Hull, Hutchison, and Strasser). Understanding the manufacturing and distribution costs that are figured into the price of a CD is important because it contributes to the market value of the CD. This is not to say that some costs should not be higher. For instance, it is likely that the record store clerk makes slightly above minimum wage - raising the price of the retail price may contribute to higher wages for the clerk. 
At first glance, the Internet appears to be a medium through which music can be distributed without having to rely on a great deal of physical infrastructure such as a brick-andmortar store. As Mark Fox describes:

Technological changes have heightened competition for the major labels. The distribution of music over the Internet requires only a single master copy, whereas distribution of music as a physical product requires producing, shipping, and warehousing CDs, audio cassettes, etc. When music is stored and sold as a computer file, disintermediation (the cutting out of middle layers of distribution channels) occurs. (204)

For the price of network access and server space, a musician can distribute his/her music internationally without having to pay the costs of printing, storing, shipping, and selling the product - all part of a physical infrastructure. One of the most promising and disturbing aspects of the Internet is disintermediation because eliminating intermediaries means that the cost to compete is lowered, but it also means that jobs are removed from the economy. An ideal disintermediation would eliminate expensive entrance barriers, but would also create new employment for workers who held jobs that support CD distribution.

Theoretically, Internet access gives both fans and musicians the opportunity to interact in a direct way that was previously only possible at live shows. This conception of the Internet is what Henry Jenkins heralds as "convergence culture, where old and new media collide, where grassroots and corporate media intersect, where the power of the media producer and the power of the media consumer interact in unpredictable ways" (2). People have the liberty to post whatever media content (within copyright law) they choose on the Internet and scholars like Jenkins have been quick to presume that this is the end of the tightly controlled media industry, 
as we know it. This is the main point of authors such as McLeod and Matthew David; artists from Wilco to Radiohead and Ani DiFranco to the Artic Monkeys are using the Internet to better connect to fans. As fans connect with these artists online, they are attending more shows and buying more music and merchandise. Jenkins goes as far as comparing the current Internet technological uses to folk and do-it-yourself cultures where everyone can be an interactive participant in creating culture (132). The only logical end to such conjectures is the complete liberation of producers and consumers from their separate roles in cyberspace. However, these authors always point to the same handful of exceptions to the rule, which only reinforces the existence of the rule. Yes, Radiohead was very successful at giving away their music online for donations, but why were they successful? Yes, several artists (e.g. Artic Monkeys) have foregone major record contracts and still sold millions of albums, but why has this happened for them and not others? The main question that needs to be asked is if I released an album the same way, would I get the same results? Most likely not because these exceptions to the rule have succeeded because of already established popularity.

There should be no expectation for the allocation of power in media industries to change just because the media delivery method has changed. For example, C. Edwin Baker demonstrates empirically how major news outlets have used the Internet to increase readership (108). Baker's main argument is that reducing distribution costs encourages the major news outlets to invest more in "first copy costs" (i.e., production values) because, with wider distribution, these costs can be recouped across a larger audience. But by encouraging majors to invest more in first copy costs, this paradoxically has the effect of driving out less well-financed competitors (who cannot afford to invest as much in content/production values). All things being equal, Baker demonstrates that audiences prefer commodities with "more inputs" than those with less. This is 
significant because it demonstrates that media corporations remain the dominant players despite supposedly unlimited choices on the Internet. Baker is willing to concede that "reduced distribution costs lower a significant barrier to entry into the commercial content market" (101), but also argues that lowered barriers create an environment where there can be too much content for consumers to decipher.

In the recording industry, we would expect to see a rise in the market share of independent labels if the Internet is providing better access to consumers for independent labels and artists. However, the recording industry's data demonstrate that the major record labels have increased their market share relative to independent labels because as Figure 1 demonstrates, market share of independent record labels has decreased since 1996. According to Nielsen SoundScan, independent labels were $20.3 \%$ of the US market in 1996, but in 2010, their market share had dropped to a low of $9.85 \%$. Rather than increasing as a result of Internet distribution, independent labels are actually having a more difficult time competing with major record labels. When consumers are confronted with access to everything on the Internet, they are forced to retreat to distribution systems that they recognize in order to find content; this is where branding and the effects of "old media" power come into play—majors can use control over "old media" (TV) to drive business to their online commodities. The RIAA contends that disintermediation only causes harm through music piracy; however, the RIAA fails to articulate the industry's role in the process of disintermediation. 


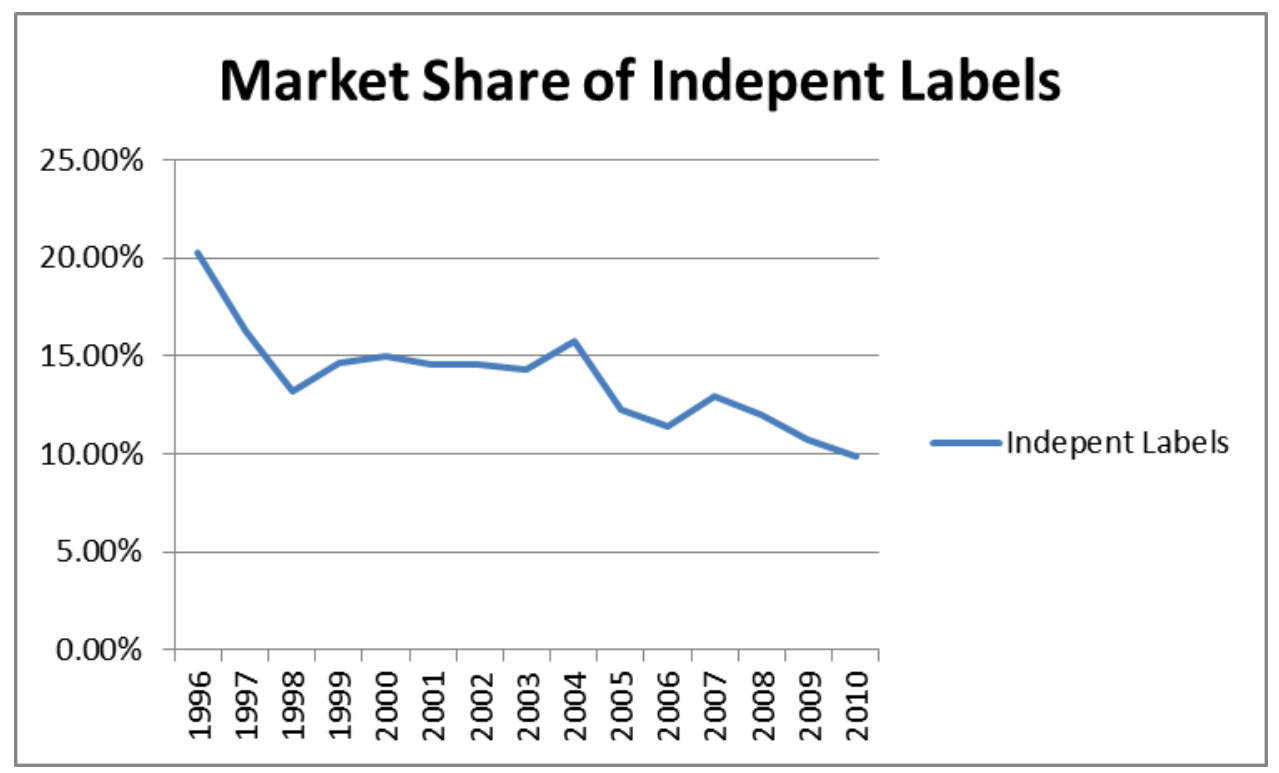

FIGURE 1 - MARKET SHARE OF INDEPENDENT LABELS (NIELSEN 1996-2011) ${ }^{2}$

From 2 p to iTunes

Digitizing music created possibilities for the distribution and storage of music, but digitization was initially directed by people with software experience rather than record label executives. After people discovered that they could "rip" music from CDs and store music in digital format on their computers, the floodgates were opened for people with computer programming skills to discover new ways to share music with their friends. The music exchange culture has been around since music listeners could first create mixtapes for cassette players in the late 1960s-70s, but the digitization of music has meant that music can be copied repeatedly without any loss of quality. The two dominant forms of mass distribution of music on the Internet have been peer-to-peer file sharing (p2p) and online music stores. However, the development of iTunes, along with the RIAA's litigation against file sharers, has given online music stores a structural advantage to distribute music on the Internet.

File sharing was developed out of the same cultural logic as creating mixtapes. People that collect music tend to enjoy listening to and talking about that music with friends; if a 
person's friends did not have the means to purchase music, the person with the music would create mixtapes for the others. Since copies of analog tapes are of lower quality with each copy, these copies were never really seen as a viable alternative to purchasing new tapes and vinyl records. The RIAA was aware of mixtapes, but there was little they could do aside from litigate the manufacturers of tape recorders because there was no way to prosecute individuals who were exchanging mixtapes. Rather, the RIAA focused legal efforts on tape piracy in the Global South (Karaganis). Whereas mixtapes were generally considered benign, and the recording industry focused its legal efforts on prosecuting large-scale piracy facilities, file sharing became a perceived threat to the longstanding business model of the major record labels.

Peer-to-peer software allows people to access the music collections of a vast network of music fans. The users on a $\mathrm{p} 2 \mathrm{p}$ network construct what amounts to an amorphous library that shifts according to the users who are online sharing music at a given time; therefore, a larger quantity of people online expands the diversity of the music available. Since the music available on $\mathrm{p} 2 \mathrm{p}$ networks is not static, $\mathrm{p} 2 \mathrm{p}$ networks have to be measured by the number of users online. It is important to recognize that $\mathrm{p} 2 \mathrm{p}$ software is not limited by content rules, but rather by what users contribute to the network. The effect that this has had on access to music is two-fold: (1) it has given any musician equal access to the market regardless of whether they are on a record label; (2) p2p software has also, paradoxically, given record labels a tool that they can use to eliminate the scourge of mixtapes or music sharing (Lessig). Users on $\mathrm{p} 2 \mathrm{p}$ networks create the most democratic form of music distribution.

While some forms of file sharing on $\mathrm{p} 2 \mathrm{p}$ networks may cause a loss of some profit for musicians, it is not clear that this is the case for all musicians. United States Federal Courts have decided to shut down $\mathrm{p} 2 \mathrm{p}$ services based on perceived harm done to musicians; however, 
Lawrence Lessig warns that this is an oversimplification of an issue that requires the law to weigh the harm against the potential benefits of file sharing. Lessig lays out four types of content that file sharers share using p2p software. (A) First, there are people who use file sharing software to download content instead of buying it. (B) Second, some file sharers use the networks to sample music that they purchase after having decided that they enjoy it. (C) Third, people use the networks to find music that is no longer available at stores (this makes the network most similar to a library). (D) Fourth, people use file sharing software to find music that is either not copyrighted or permitted to be available on the Internet for free (Lessig 68-69). Each type of use has a different level of legality, but it is clear that the four uses are not equivalent to each other.

Most of the case law dealing with file sharing, so far, focuses mainly on Lessig's type A content use. The federal courts have been willing to place most of the weight on the harm caused to copyright holders who have their music downloaded by people who lack any intent to purchase the music, most visibly in A\&M Records, Inc. vs. Napster (2001). These users are the people who the RIAA continually refers to as "pirates" because the RIAA claims that these file sharers are violating copyright law by not having authorization to upload or share their music libraries. There is an important distinction here between downloading music and uploading music. According to the RIAA, a person who uploads files on a p2p network is similar to one who makes unauthorized copies of a copyrighted $\mathrm{CD}$ and sells them. However, when someone downloads music, copyright law views this person similar to someone who purchases a pirated CD. Since copyright law is concerned with the unauthorized reproduction or copying of protected material, digital music pirates are the people who share (i.e. distribute), by way of 
uploading, music with others; therefore, it is possible to use $\mathrm{p} 2 \mathrm{p}$ software strictly for downloading and avoid being sued by the RIAA.

Lessig's type B content use presents an interesting dilemma for record executives because it opens up the possibility of users purchasing music after they have sampled it for free. The recording industry may not want to limit this category as it has the possibility of increasing album sales. Furthermore, there is evidence to suggest that record labels have been collecting consumer data from file sharing networks to track user statistics (Howe). For example, BigChampagne is one firm that has developed software to track statistics on users by crawling through their searches, collecting information on their libraries and matching this information with part of their IP addresses to estimate their geographic location (Buskirk). The information that record labels gain from services such as BigChampagne is then used to encourage radio stations to play a song more because of its popularity on $\mathrm{p} 2 \mathrm{p}$ networks. When record labels know that a song is being heavily downloaded in an area, they can pressure radio stations to play their music and find other ways to monetize their artists' music (Buskirk). For instance, if an artist has a popular download in a specific city, the record label could book a concert for that artist in that city and capitalize on his/her popularity without selling an album.

Content use type $\mathrm{C}$ is the one that Lessig sees as "the most rewarding for many" (68) because it gives people the opportunity to find content that is no longer being published. It is this type of use that is most similar to that of a library; works can be found on the Internet that otherwise would be nearly impossible to find in a store because they are out-of-production. This type of "sharing is illegal, yet good for society (since more exposure to music is good) and harmless to the artist (since the work is not otherwise available)" (Lessig 69). Here, Lessig means that this type of file sharing is "good for society" not for some intrinsic value of music, 
but rather, because libraries serve the public good. From Lessig's perspective, making this content available online constitutes a public good that needs to be balanced against those people who illegally download music that is available to purchase without the intent to buy it. However, as soon as out-of-print copyrighted music becomes commercially available on the Internet, the public good argument loses traction as that music falls under type A.

While Lessig's arguments about the first three types of content use are persuasive, type D is the most compelling on its own. This fourth type takes into account that "there are many who use sharing networks to get access to content that is not copyrighted or that the copyright owner wants to give away" (Lessig 69). Musicians and other copyright holders have reasons why they would like to make their music available to consumers for free; primarily, musicians that do not have record contracts can use the disintermediation allowed by $\mathrm{p} 2 \mathrm{p}$ technology to distribute their music to consumers who would otherwise have no means of hearing that music. "Some artists," Tarleton Gillespie reasons in Wired Shut, "began posting their own music in mp3 format, especially those without major label contracts, hoping the Internet might help loosen the corporate stranglehold over popular music and forge a more direct connection between artist and fan" (41). File sharing becomes a means for independent artists to subvert the oligopoly that major labels have over the music distribution infrastructure. Furthermore, by allowing musicians to post their work free online, they may be starting a new alternative to a capitalist distribution system. This is the most democratic use of $\mathrm{p} 2 \mathrm{p}$ technology as it allows for the free use of content without the need to have expensive distribution systems to get the content to consumers.

Whereas Lessig wants these uses balanced against each other, the more troubling aspect dealing with type D content use is that it is rarely discussed. The RIAA and the press alwaysalready assume that any and all file sharing is a violation of copyright law. It is presumed that the 
only interests at stake in debates over file sharing are those with capital invested in music. The real advantage of $\mathrm{p} 2 \mathrm{p}$ networks is that they allow people to promote their own copyrighted material on the Internet for free. There has been a presumption of illegality in the discourse about file sharing even though the courts have not explicitly taken this position. For instance, in $A \& M$ Records, Inc. vs. Napster, the Ninth Circuit of Appeals ruled that Napster had to shut down because it was designed with the intent to circumvent copyright legislation (Langenderfer and Cook); Kazaa received a court injunction for a similar reason. Neither of these rulings, however, precludes other $\mathrm{p} 2 \mathrm{p}$ services from being developed and operated. Napster was shut down because it used a central server that the plaintiffs argued could be used to stop the flow of copyrighted material. Kazaa, which did not use a central server, lost its case because developers marketed it as something that could circumvent copyrights. However, any discussion of technology and the law that does not address the social nature of both, fails to understand why technologies and laws exist. First, technology has no use by itself, so there is no reason to connect a piece of software with a particular social activity or use (Gillespie). Second, the law is a social construction that involves compromise by a set of actors; in Digital Copyright, Jessica Litman describes, in relation to copyright law, the people with the most power to develop the law are those people that had a say in previous manifestations of the law. As a result, there are anomalies in the application of copyright law. These technologies and laws in turn deter people from uploading music to their $\mathrm{p} 2 \mathrm{p}$ accounts. ${ }^{3}$ If people use $\mathrm{p} 2 \mathrm{p}$ networks, but do not upload music, then the music libraries from which other users can download is limited in size, and Lessig's type D becomes less potent.

By creating uncertainty over the legality of uploading/downloading music under the type A content use, the RIAA has limited the availability of the other three types of content use. There 
has been a consistent use of arguments about copyright infringement to limit the use of $\mathrm{p} 2 \mathrm{p}$ software and services. File sharers are not always clear about what constitutes an illegal use of file sharing and some people avoid using p2p networks to circumvent any threat of lawsuit (Madden and Lenhart). As described above, the less people that use p2p networks (and even fewer who actually upload content), the less diversity of content that is available for users (Baker). At their pinnacle, $\mathrm{p} 2 \mathrm{p}$ networks represented an opportunity for users to circumvent the economic hegemony of record labels, but lawsuits have disrupted the free flow of information to consumers. Now, lawsuits are no longer necessary and the RIAA stopped pursuing them in 2009, since consumers have habituated their consumption to new digital intermediaries.

\section{Enter iTunes}

Major record labels have realized that the digital distribution of music is not going to go away, but they have always been adept at using transmediations for their benefit. iTunes and other online music stores create a platform to direct digital content towards consumers while generating profits for major record labels. When $\mathrm{p} 2 \mathrm{p}$ software was developed, the Internet lacked a means of charging consumers for content consumption. File sharing was an open platform technology that took into consideration the interests of people that used the Internet instead of people that controlled the content. In the autonomist Marxist tradition, the software developers could be seen as "active agents who persistently contest capital's attempts at control" (DyerWitheford 70). Developing technologies that circumvent capital is part of the "circulation of struggles" between capital and labor. However, the most powerful interest is always the owner of the means of production, and in this case, record labels were quick to develop alternative and proprietary technologies before they lost their relevance and power. The result has been an 
overwhelming move to online music consumption, primarily through Apple's iTunes music store.

Apple, inc. first released iTunes in 2001 as a piece of proprietary software for Apple computers that could play music on a user's hard drive or CD-drive. iTunes 1.0 was intended to serve the same function on Apple computers as Windows Media Player did on PCs. iTunes Version 4.1 allowed for Windows compatibility and created the iTunes Music Store. The iTunes Music Store, launched in 2003, at first allowed users to purchase mp3s (in the case of iTunes they are in the AAC format) for $\$ 0.99 /$ song or about $\$ 9.99 /$ album (the album price has always been variable).

Quickly, iTunes grew to have the largest library of any of the online music stores giving it a competitive edge over its competitors with over 13 million songs available to download. ${ }^{4}$ The other model for online music consumption has been streaming subscriptions (such as Rhapsody), but these models have struggled to keep pace with the market share of iTunes. In 2011, iTunes sold $38.23 \%$ of the retail music market-share, while its two closest competitors, Wal-Mart and Best Buy combined to hold $17.86 \%$ of the retail market (Christman). Other online music retailers' share of the music retail market pale in comparison to retailers who sell albums/songs Rhapsody leading with $1.94 \%$ share (Christman). The significance of the size of its library makes iTunes the "Wal-Mart" (Baker) of online music stores. If a consumer knows that iTunes has the largest number of songs available for download, he/she will go to iTunes first; it is not rational to begin searching for a song on a smaller site. Rather, consumers are likely to look at other sites only if they do not find what they are looking for on iTunes or if they are looking for a specific niche genre. However, iTunes was not the sole product of Apple's ingenuity; it was also the result of the recording industry's desperate need to compete with free music online. 
In 2003, the RIAA wanted to make its presence and willingness to fight against illegal downloading known and it began filing lawsuits against users for downloading copyrighted material that its members owned. It has been difficult to tell if these lawsuits follow due process of law because the decisions of when the RIAA chooses to file litigation against an individual are unknown to the public. One of the reasons that the details about these lawsuits are unknown is because most of the cases do not make it to trial. The RIAA sues for the maximum amount of statutory damages allowed by law and threatens that if the defendants do not accept a settlement, the legal fees will be more than the defendants can afford (Lessig). These lawsuits have a panoptic effect on people who illegally share music because they know they are being watched, but they do not know when they are being watched. Mark Poster describes this type of panopticon as a "superpanopticon" because it is no longer limited by physical boundaries - the digital panopticon has the capacity to follow a user's every digital move (Poster). The effect is that people weigh the costs of being sued for an inordinate amount of money against the benefit of downloading a few songs.

Part of the reason why so many people were participating in the unauthorized downloading of music was that there was no "legitimate" way for them to purchase music online (IFPI). Internet music stores were approached initially with caution by the RIAA and major record labels because mp3 files could easily be uploaded to p2p networks. Early online music stores were closed by the RIAA; for instance, MP3.com, one of the first online music stores, was shut down eventually because of industry dissatisfaction with the way the store operated. Users could purchase music on MP3.com and access those songs from any computer via the Internet on My.mp3.com - one of the earliest cloud computing databases for music. Furthermore, My.mp3.com allowed users to access other music that they already owned via "the cloud" by 
loading a CD on their computer to demonstrate to MP3.com that they owned a song. The RIAA argued that the use of files on other computers constituted an unauthorized reproduction of music in violation of copyright law; the music industry has been trying to redefine the purchase of music to be a one-time non-transferable transaction that limits the purchase to a definite medium (Gillespie). Coincidentally, MP3.com's My.mp3.com operated in the exact way as iCloud, but Apple's iCloud negotiated a contract with the major record labels prior to its release. The music industry wanted to make sure that its interests (i.e. profits) were served by any new online music distribution system.

Once music is digitized, it can be transferred from one computer quickly and easily, so the music industry had to create software to slow the flow of content. To limit and track movement of protected content on the Internet, record labels began imbedding Digital Rights Management (DRM) on mp3 files. After Congress passed the Digital Millennium Copyright Act (DMCA) in 1998, it became illegal for content users to attempt to circumvent DRM except in limited circumstances. This created an environment where a business could create an online music store that "protected" most music from unauthorized reproduction.

In 2003, the same year that the RIAA began suing file sharers, the iTunes Music Store was launched to provide legal downloads for Internet users at $\$ 0.99 /$ song. The timing of the launch of iTunes with the crackdown by the RIAA was convenient because it gave people a place to download digital music without risking a lawsuit. In fact, Steve Knopper's Appetite for Self-Destruction illustrates the discussions between label executives, Steve Jobs, and the RIAA about the decision to license iTunes and begin filing lawsuits against individuals. The RIAA had been filing lawsuits against online music distributors since 1998, but waited until 2003 to take 
action against individual file sharers. These lawsuits acted as a catalyst for music consumers to find a way to download music through authorized/licensed sites.

The creation of the iTunes Music Store had a direct and immediate impact on all four of Lessig's content use types. File sharers who download music as a substitute for purchasing it, type A, are affected most directly by iTunes. They lose their ability to argue that songs in the iTunes database are not available from the comfort of their home. In addition, record labels can argue that the ostensibly low price of downloading from iTunes gives them plenty of buying power. A few highly reported lawsuits by the RIAA of this first type of file sharer can scare a large number of file sharers into becoming avid iTunes customers.

Lessig's Type B content use for file sharers becomes irrelevant with the creation of iTunes. Customers of the iTunes store can listen to a thirty-second sample of any song in the iTunes library. This does not give unlimited access for users to sample content without purchasing the music, but it does give customers an idea of the sound of the music. Furthermore, the Internet, in general, contains streaming versions of a far greater number of songs than is available on iTunes. If people want to sample music, a search on Google will generally yield results from MySpace music, YouTube.com, last.fm or a number of other resources. While the second type of content use was always benign to music industry profits (if not outwardly beneficial), it has become increasingly banal and irrelevant as users can sample music in any number of ways.

It is through type $\mathrm{C}$ content use that iTunes changes digital music consumption so much from Lessig's argument. Lessig envisioned file sharing as a way for users to share out-ofproduction music in what would end-up resembling a digital museum of music. Since copyright owners no longer had a means to sell their works, Lessig figured that this type of use was similar 
to reselling a used $\mathrm{CD}$ or book (71). However, the virtually limitless server capacity of the iTunes database makes it cost effective for record labels to sell previously out-of-publication music (from their deep catalogs) at a negligible cost. From a business standpoint, there is no longer a reason for this music to be provided for free because it can be sold without the high cost of printing only a few copies of a particular album. The public good that Lessig saw in making hard to find recordings available is negated with the advent of online music stores.

Copyright owners who want to distribute their music on $\mathrm{p} 2 \mathrm{p}$ networks for free (type $\mathrm{D}$ content use) lose the most with the development of iTunes because musicians cannot upload their music on iTunes for distribution without the help of an intermediary. These intermediaries charge a fee to have music placed on iTunes and other online music retailers. CD Baby is one intermediary that independent musicians can use to get their music to online retailers (i.e. iTunes). This service distributes members' music to online retailers, acts as an independent music store, provides CD printing services, and can get music distributed to brick-and-mortar stores. Musicians can join CD Baby by paying a onetime $\$ 35$ warehousing fee. This creates great opportunities for independent musicians, but it does not come for free. Intermediaries take a percentage of sales earned on each download; for instance, CD Baby takes 9\% of all profits from downloaded music and $\$ 4$ for every album sold (regardless of how much the album sold for); note that musicians with major label record contracts do not have to use such an intermediary. These fees are in addition to the retail revenue that iTunes takes for bringing music to market. Furthermore, the default settings on iTunes point users to music by artists who are signed to the major record labels. Consumers are far more likely to remain on default screens than to search for more obscure content (Vaidhyanathan). Ostensibly, musicians can still upload music on p2p networks if they choose to, but these services have been so decimated by lawsuits ${ }^{5}$ and the pull 
towards online music stores that they no longer have the vast user-base that brought the networks so much exposure. Sharing music on a $\mathrm{p} 2 \mathrm{p}$ network allowed musicians and copyright holders to get their music to listeners without the listener having to take a gamble by purchasing previously unknown music. Now, independent musicians can sell their music online, but they have to pay fees to get the music carried.

\section{Monopoly/Oligopoly in the "Digital Age"}

Media concentration has created an overwhelming barrier for independent musicians to overcome in order to compete on a "free" market. Four record labels, known as the "big four," currently control the vast majority of artists. Furthermore, the major record labels' relationship with these artists are generally structured similar to that of a plantation owner with sharecroppers ${ }^{6}$ (Slichter). Overwhelming market share gives the major record labels and their affiliates the capital necessary to propel their artists up the Billboard charts through heavy promotion. Music production is about the bottom line profit for these large corporations and their goal is to keep potential competitors out of the market.

When it finally became apparent to the major record labels that file sharing may be contributing to a loss in profits, their reaction was first to cut their losses by fighting $\mathrm{p} 2 \mathrm{p}$ networks and later develop a way to become profitable once again. As Jenkins recalls from the New Orleans Media Experience conference/festival in October 2003, whereas people from the game industry were excited by the prospects of the Internet, the recording industry was panicked:

The record industry types were sweating bullets; their days were numbered unless they figured out how to turn around current trends (such as dwindling audiences, declining sales, and expanding piracy). The panel on "monetizing music" was one of the most heavily attended. Everyone tried to speak at once, yet none of them 
were sure their "answers" would work. Will the future revenue come from rights management, from billing people for the music they download, or from creating a fee the servers had to pay out to the record industry as a whole? ... Perhaps the money will lie in the intersection between the various media with new artists promoted via music videos that are paid for by advertisers who want to use their sounds and images for branding, with new artists tracked via the web that allows the public to register its preferences in hours rather than weeks. (9)

Four distressing ideas emerge from Jenkins' description of recording industry personnel at this conference panel. First, there is a sense of entitlement among major record labels for their monopoly in the market. Second, music industry leaders fail to recognize the actual causes of slipping earnings and profits. Third, executives are concerned primarily with generating profits instead of finding new innovative ways to distribute music. Fourth, Jenkins thinks that the answer is in synergy: the monopolization of media companies across media platforms.

The pretense to this discussion is that if the big four are losing money, then it must be because the money is being stolen from somewhere. Free market capitalism is based on the idea of the survival of the fittest in the market, until the industry leaders begin to struggle to remain on top. When the major record labels began to see declining profits, they pointed to online music piracy as the culprit for their projected losses; however, one of the reasons for the decline in record sales is that the transmediation from CDs to mp3s did not require people to buy mp3s of music that they already owned (Kohli). In the switch from vinyl records, to cassette tapes, to CDs, consumers would buy content that they already owned in new media formats (this is known as residual album sales), but with the switch from $\mathrm{CDs}$ to $\mathrm{mp} 3 \mathrm{~s}$, the music can be ripped from a CD directly to a computer hard drive. The music industry has always relied on residual album 
sales as a result of these transitions (Park). At the same time that $\mathrm{p} 2 \mathrm{p}$ file sharing became popular, record labels were beginning to see residual sales finally dry-up from the change to CDs. By pointing to a loss in sales from consumers who rip mp3s, record labels are assuming that they are entitled to profits from new media formats when users already own content in a different format.

The big four are concerned with continually finding new ways to create capital despite new technologies that allow others to compete for listeners. They are willing to use their economic power to create a favorable atmosphere where they can continue to keep competition out of the market. Copyright has become the tool that the recording industry uses to restrict competition on the market. "Copyright is no longer about creative expression and the protection of that expression by the law - the original intention of the law. It is about protecting the monopoly, which the law gives copyright owners who are big contributors to GDP" (Kohli 14). The music industry uses copyright statutes to maintain its viability instead of fostering creativity. Part of the way that the big four have been able to maintain this oligopoly has been the barriers that independent musicians have to overcome to compete. With the development of $\mathrm{p} 2 \mathrm{p}$ software, major record labels were quickly losing their grasp on the control over access to the industry. Without long-term structural changes to the music industry, the major record labels realized that they would no longer have a viable business model. Instead of encouraging competition, the music industry realized that its advantage on the market was in the construction of economic barriers to entrance into the market. For years, the big four had maintained their oligopoly by being the only companies that could afford large-scale distribution, so they used the RIAA to enforce copyright law while technology was developed to recreate these barriers on the Internet. 
iTunes created the entry barriers needed for the big four to maintain their control of the music industry. Since people cannot directly upload their music to iTunes for others to download, the major labels can force musicians to pay a fee (through intermediaries such as CD Baby) to compete for album sales. These fees act to recreate the sunk costs that the major record labels already have in their physical distribution systems. The major record labels are then free to contract directly with iTunes to determine how much they have to pay to have their music available on the online music store. This allows the major record labels to maintain their dominance in the music market.

\section{Conclusion}

Techno-utopians have heralded the Internet as a technology that can generate equality by lowering barriers for people to access information, while increasing the speed at which Internet users can communicate. However, the Internet has increasingly become a place where goods are delivered to consumers in their home; a mall that one can never escape. Whenever the Internet seems like it can foster equality, big business reasserts its dominance. Nowhere is this clearer than in the music industry's reappropriation of digital technology to sell music on the Internet.

iTunes was the music industry's response to what it constructed as rampant criminal behavior in the form of $\mathrm{p} 2 \mathrm{p}$ file sharers violating copyright law by downloading music from one another. Digital distribution also opened an avenue of competition for independent musicians hitherto to unknown to the major record labels because independent musicians did not have the money that it takes to distribute music to physical stores across a large geographic area. Theoretically, file sharing put major record labels on equal ground with independent musicians. By creating an easy to use online store and suing file sharers, the major record labels could once again direct consumers to a place where they held the power. While iTunes gives independent 
musicians more opportunity to distribute music than before online distribution became possible, it lends itself to concentrating power in the major record labels. The walls that digital distribution broke down have been replaced by distribution barriers in the form of iTunes. 


\section{Notes}

${ }^{1}$ It may seem odd that it costs money to sell albums at stores, but store managers are not willing to place every album ever recorded on their shelves. With limited shelf space, managers want to make sure that the music that they have at their stores sells, which is typically related to the amount of marketing that an album receives.

${ }^{2}$ Nielsen SoundScan refers to "other labels" in its publications. Here, I am using "independent labels" because independents are the labels not listed in these publications; for instance, the 2011 publication refers to Sony, Warner, Universal, EMI, and "other labels."

${ }^{3}$ The Pew Research Center's Pew Internet \& American Life Project surveyed p2p users' practices following the RIAA's lawsuits against individuals. They found that users showed a dramatic decline in file sharing (i.e. uploading their music library) following these lawsuits (Madden and Lenhart).

${ }^{4}$ As of 20 November, 2010, iTunes had over 13 million songs available in its catalog ("Bits \& Briefs," 2010).

${ }^{5}$ According to The Pew Internet \& American Life Project a precipitous decline of file sharing occurred between June 2003 (when the RIAA announced its plans to file sharers) and November 2003, (Madden). While file sharing usage has periodically risen and fallen since that time, the Pew tracking data over time demonstrate that less people file share as a result of the RIAA's campaign.

${ }^{6}$ Artists are signed and given an advance to record an album that must be repaid through sales. This offloads risk onto the artists themselves. Furthermore, artists do not receive revenue from sales until all advanced funds are recouped. 


\section{$\underline{\text { Works Cited }}$}

Baker, C. Edwin. Media Concentration and Democracy: Why Ownership Matters. New York: Cambridge University Press, 2007. Print.

“Bits \& Briefs." Billboard 20 Nov. 2010: 10-10. Print.

Burkart, Patrick, and Tom McCourt. Digital Music Wars: Ownership and Control of the Celestial Jukebox. New York: Rowman \& Littlefield Publishers, 2006. Print.

Buskirk, Eliot Van. “Inside BigChampagne's Music Panopticon.” Wired.com. 5 Aug. 2009. Web. 20 Sept. 2009.

Chapple, Steve, and Reebee Garofalo. Rock " $n$ " Roll Is Here to Pay: The History and Politics of the Music Industry. Chicago: Nelson-Hall, 1977. Print.

Christman, Ed. "ITunes on Top, Again." Billboard 12 May 2012: 8-8. Print.

David, Matthew. Peer to Peer and the Music Industry: The Criminalization of Sharing. Los Angeles: Sage Publications Ltd, 2010. Print.

Dyer-Witheford, Nick. Cyber-Marx: Cycles and Circuits of Struggle in High-technology Capitalism. Urbana: University of Illinois Press, 1999. Print.

Fox, Mark. "E-commerce Business Models for the Music Industry." Popular Music and Society 27.2 (2004): 201-220. Print.

Frith, Simon. "The Industrialization of Popular Music." Popular Music and Communication. 2nd ed. Ed. James Lull. Newbury Park, Calif.: Sage Publications, 1992. 53-79. Print.

Garrity, Brian, and Ed Christman. "RIAA Figures Show Continuing Decline." Billboard 13 Sept. 2003: 6-7. Print.

Gillespie, Tarleton. Wired Shut: Copyright and the Shape of Digital Culture. Cambridge, Mass.: MIT Press, 2007. Print.

Howe, Jeff. "BigChampagne Is Watching You." Wired.com. 10 October 2003. Web. 25 Sept. 2009. 
Hull, Geoffrey P., Thomas W. Hutchison, and Richard Strasser. The Music Business and Recording Industry: Delivering Music in the 21st Century. 3rd ed. New York: Routledge, 2011. Print.

International Federation of Phonographic Industries. "Recording Industry in Numbers." London: IFPI, 2002. Print.

---. "Recording Industry in Numbers." London: IFPI, 2005. Print.

Jenkins, Henry. Convergence Culture: Where Old and New Media Collide. New York: New York University Press, 2006. Print.

Karaganis, Joe, ed. Media Piracy in Emerging Economies. First. New York: Social Science Research Council, 2011. Print.

Knopper, Steve. Appetite for Self-Destruction: The Spectacular Crash of the Record Industry in the Digital Age. New York: Free Press, 2009. Print.

Kohli, Vanita. "Mutilating Music: a Critical Look at the Copyright a Business Issues in Online Music Distribution." Entertainment Law Review 12.1 (2001): 15-24. Print.

Langenderfer, Jeff, and Don Lloyd Cook. “Copyright Policies and Issues Raised by A\&M Records V. Napster: 'The Shot Heard "Round the World" or "Not with a Bang but a Whimper?"”. Journal of Public Policy \& Marketing 20.2 (2001): 280-288. Print.

Lessig, Lawrence. Free Culture: The Nature and Future of Creativity. New York: Penguin Press, 2004. Print.

Litman, Jessica. Digital Copyright. Amherst, N.Y.: Prometheus Books, 2006. Print.

Madden, Mary, and Amanda Lenhart. Sharp Decline in Music File Swappers. Pew Research Center, 2004. Pew Internet \& American Life Project.

McLeod, Kembrew. "MP3s Are Killing Home Taping: The Rise of Internet Distribution and Its Challenge to the Major Label Music Monopoly." Popular Music and Society 28.4 (2005): 521-531. Print.

Negus, Keith. Music Genres and Corporate Cultures. New York: Routledge, 1999. Print. 
Park, David J. Conglomerate Rock: The Music Industry's Quest to Divide Music and Conquer Wallets. Lanham, MD: Lexington Books, 2007. Print.

Poster, Mark. The Mode of Information: Poststructuralism and Social Context. Chicago: University of Chicago Press, 1990. Print.

Slichter, Jacob. So You Wanna Be a Rock \& Roll Star: How I Machine-gunned a Roomful of Record Executives and Other True Tales from a Drummer's Life. New York: Broadway Books, 2004. Print. Nielsen Company. SoundScan 1996 Year-end Music Industry Report. Los Angeles: Nielsen, 1997. Print. ---. SoundScan 1998 Year-end Music Industry Report. Los Angeles: Nielsen, 1999. Print. ---. SoundScan 2000 Year-end Music Industry Report. Los Angeles: Nielsen, 2001. Print. ---. SoundScan 2002 Year-end Music Industry Report. Los Angeles: Nielsen, 2003. Print. ---. SoundScan 2004 Year-end Music Industry Report. Los Angeles: Nielsen, 2005. Print. ---. SoundScan 2006 Year-end Music Industry Report. Los Angeles: Nielsen, 2007. Print. ---. SoundScan 2010 Year-end Music Industry Report. Los Angeles: Nielsen, 2011. Print. Vaidhyanathan, Siva. The Googlization of Everything. Berkeley: University of California Press, 2011. Print. 